learn that it has lately been found at one of the Caldbeck Fell mines, in Cumberland, associated with Pyromorphite, Anglesite, and various other ores of Lead. As Molybdenite is rather common in some of the adjoining mines, the occurrence of Molybdate of Lead might, perhaps, have been expected, as a result of the decomposition of Molybdenite and Galena.

Another mineral new to the British list has just been detected in the Hæmatite mines of the Cleator district. This is Hausmannite, which occurs, well crystallized, in small pockets and veins associated with Pyrolusite, mostly between the hæmatite and the limestone in which it is found.

Further notices of these minerals will appear in the Memoirs of the Geological Survey.

J. G. GoodCHILD.

Penrith, 9th October, 1875.

\title{
PRISMATIC STRUCTURE OF BASALT.
}

SIR, -Assuming the description of the three basaltic prisms in the collection of the Geological Society as given by Mr. Scrope to be exact (see Grox Mag. 1875, Decade II. Vol. II. p. 412), the facts do not in any way conflict with the explanation that $I$ have given of the mode of production of the lenticular cross-joints in basaltic prisms. The prisms referred to must have come from that part of the original mass in which occurred the dividing surface between that part cooled from the top and that cooled from the bottom of the mass, as is proved with respect to one of the prisms by the existence in it of a joint having surfaces concave in both directions, such plane in fact passing horizontally through this articulation; other adjacent prisms may have their joints, within certain limits above or below this plane, either convex upwards or downwards, for the slightest differences in the conductivity or conditions and rates of cooling will suffice either to depress or elevate, by a greater or less distance, the plane already spoken of. It is also not difficult to see that several alternations in the directions of the concave or convex surfaces may occur in the neighbourhood of the meeting plane of cooling in opposite directions, where, as in the case of other divergent or opposite keat waves, more or less confusion in normal structure must occur.

18 th October, 1875.

Robt. MaLlet.

\section{THE INVERTED STRATA OF THE MENDIPS.}

SrR,-Referring to Mr. A. M'Murtrie's interesting paper "upon certain isolated areas of Mountain Limestone at Luckington and Vobster" (read in Section C. of the late Meeting of the British Association at Bristol), wherein he showed these isolated patches to have been passed beneath and found separated from any underlying portion of the same limestone, it occurred to me at the time that the structural peculiarities of certain places I had examined would tend to explain those described in the paper, the whole of which I had not the good fortune to hear read, and therefore refrained from offering the following remarks in the Section. 